\title{
The Type III-Secreted Protein NopE1 Affects Symbiosis and Exhibits a Calcium-Dependent Autocleavage Activity
}

\author{
Mandy Wenzel, Lars Friedrich, Michael Göttfert, and Susanne Zehner \\ Institute of Genetics, Dresden University of Technology, Helmholtzstrasse 10, D-01062 Dresden, Germany
}

Submitted 25 March 2009. Accepted 3 September 2009.

\begin{abstract}
The type III-secreted proteins NopE1 and NopE2 of Bradyrhizobium japonicum contain a repeated domain of unknown function (DUF1521), which is present in a few uncharacterized proteins. A nopE1/nopE2 double mutant strain exhibited higher nodulation efficiency on Vigna radiata KPS2 than the wild type or single nopE1 or nopE2 mutants. This indicates that both proteins are effectors that functionally overlap. To test translocation into the plant cell compartment during symbiosis, NopE1 and NopE2 were fused with adenylate cyclase (cya) as reporter. A fusion with the full-length proteins or $\mathrm{N}$-terminal peptides resulted in increased cAMP levels in nodules, indicating translocation. Purified NopE1 exhibited self-cleavage in the presence of $\mathrm{Ca}^{2+}$. Two identical cleavage sites (GD'PHVD) were identified inside the DUF1521 domains. The C-terminal cleavage site was analyzed by alanine scanning. Protein variants in which aspartate or proline next to the cleavage sites was substituted displayed no cleavage. A noncleavable protein was obtained by exchange of the aspartate residues preceding both cleavage sites. Complementation analysis with the noncleavable NopE1 variant did not restore wildtype phenotype on Vigna radiata KPS2, indicating a physiological role of NopE1 cleavage in effector function.
\end{abstract}

The type III secretion system (T3SS) is a complex protein transport system of gram-negative bacteria. Many rhizobia, e.g., Bradyrhizobium japonicum USDA110, Sinorhizobium fredii USDA257, Sinorhizobium fredii HH103, Rhizobium sp. strain NGR234, and Mesorhizobium loti MAFF303099 possess a functional T3SS (de Lyra et al. 2006; Göttfert et al. 2001; Kaneko et al. 2000; Krishnan et al. 2003; Viprey et al. 1998). Whether the secreted proteins, which are called nodulation outer proteins (Nop), influence symbiosis positively or negatively depends on the host (Krause et al. 2002a; Marie et al. 2003; Meinhardt et al. 1993).

Little is known about the activity or function of secreted proteins. NopA, NopB, and NopC are components of extracellular structures of the type III apparatus (Deakin et al. 2005; Lorio et al. 2004; Saad et al. 2005). NopX is postulated to form the translocon pore in the host cell membrane (Marie et al. 2003). NopD, NopL, NopM, NopP, and NopT are supposed

M. Wenzel and L. Friedrich contributed equally to this work.

Current address for Lars Friedrich: Lehrstuhl für Biologische Chemie, Technische Universität München, 85350 Freising-Weihenstephan, Germany.

Corresponding author: S. Zehner; E-mail: susanne.zehner@tu-dresden.de

* The $e$-Xtra logo stands for "electronic extra" and indicates that two supplementary tables are published online. to be effector proteins, which are translocated into eukaryotic host cells. NopL and NopP can be phosphorylated by plant protein kinases (Bartsev et al. 2003; Skorpil et al. 2005). They are thought to interfere with host signaling cascades. NopD shows similarity to C48 cysteine peptidases (Rodrigues et al. 2007), and NopM is similar to YopM, an effector protein of Yersinia spp., which moves to the nucleus of host cells (Heusipp et al. 2006; Rodrigues et al. 2007). NopT might be a cysteine protease (Dai et al. 2008; Kambara et al. 2009).

After induction by genistein, Bradyrhizobium japonicum secretes at least 10 Nops (Hempel et al. 2009; Krause et al. 2002b; Süß et al. 2006), including NopE1 (formerly Blr1806) and NopE2 (formerly Blr1649). A translational nopE1-lacZ reporter gene fusion is expressed in mature nodules of Macroptilium atropurpureum (Zehner et al. 2008), suggesting a function of NopE1 during symbiosis. NopE1 has no obvious similarity to characterized proteins. The closest homolog is NopE2 of B. japonicum (77\% identity). Both proteins contain two conserved domains of unknown function (DUF1521). This domain is also present in hypothetical proteins of the plantassociated bacterium Burkholderia phytofirmans PsJN (accession YP_001888935) and Sphingomonas sp. strain SKA58 (accession Q1NCW0).

Here, the effector proteins NopE1 and NopE2 are studied in detail. We show their impact on symbiosis with different host plants. The translocation of these effectors into nodule cells is shown using the adenylate cyclase (cya) reporter assay. We demonstrate that purified NopE1 exhibits calcium-dependent selfcleavage, which seems to be important for effector function in vivo.

\section{RESULTS}

NopE1 and NopE2 are responsible

for a host-specific nodulation phenotype.

To test whether NopE1 and NopE2 influence nodulation, single and double mutant strains were created. Nodule formation was examined on soybean, mungbean, and Macroptilium atropurpureum. No significant difference in nodule number per plant was found between wild type and the nopE1 (BJD 4718 ) and nopE2 (BJD215) single mutant strains (Fig. 1). Nodule numbers were significantly reduced $(P<0.01)$ when soybean and $M$. atropurpureum were inoculated with a nopE1/ nopE2 double mutant (BJD $4718-215)$, suggesting that NopE1 and NopE2 have a positive effect on nodulation of these host plants.

B. japonicum shows weak nodulation capacity on the mungbean cultivar KPS2. Only six of 39 plants (15\%) were nodulated by $B$. japonicum wild type (Table 1 ). In contrast, $86 \%$ of the tested plants formed nodules when KPS2 was inoculated with the nopE1/nopE2 double mutant (BJD $4718-215$ ), indicating that 
NopE1 and NopE2 are negative effectors on this mungbean variety. In order to test whether translocation of the effectors is needed for symbiotic activity, the type III secretion mutant $\Delta 132$ was used for inoculation of mungbean. In strain $\Delta 132$, genes encoding conserved components of the T3SS are deleted and the secretion of effector proteins is precluded (Krause et al. 2002a; Süß et al. 2006). With mutant $\Delta 132,96 \%$ of mungbean plants are nodulated, suggesting that a functional T3SS is essential for NopE1 and NopE2 to act as effectors in symbiosis.

\section{NopE1 and NopE2 are translocated into plant cells.}

Although several type III-secreted rhizobial proteins have been described, formal proof that these proteins are translocated into plant cells is still lacking. Because bacteria do not
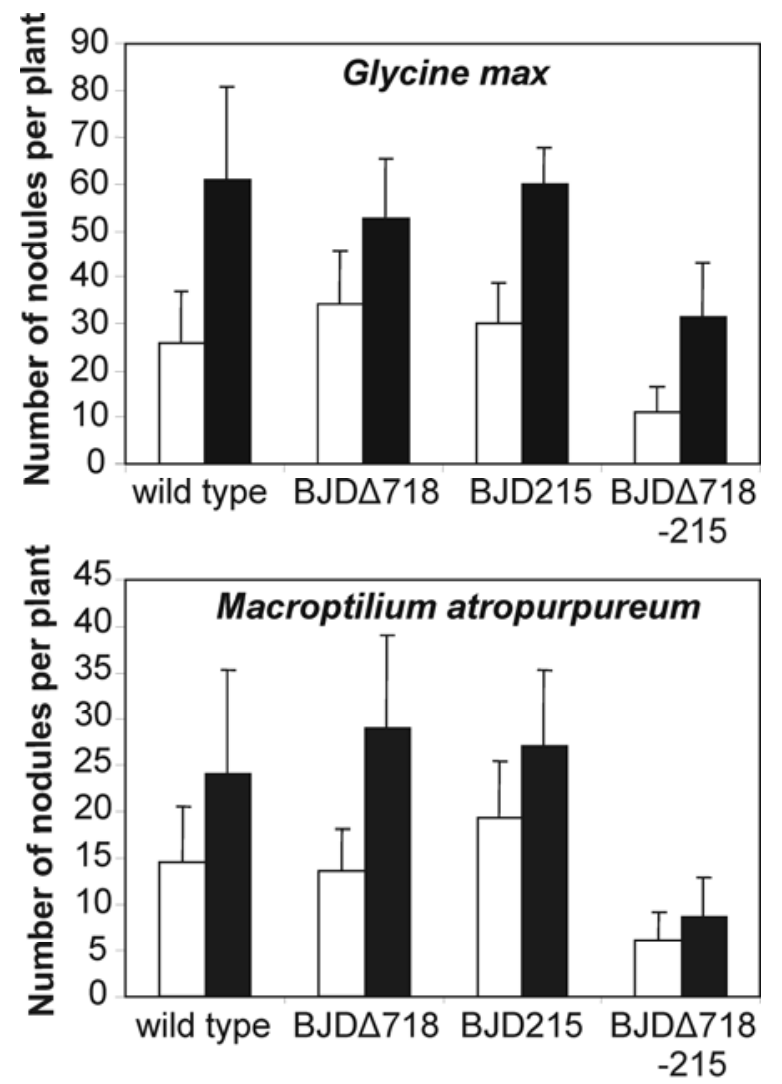

$\square 10$ days after inoculation 21 days after inoculation

Fig. 1. Nodulation properties of Bradyrhizobium japonicum wild type and mutant strains. All tested plants formed nodules. Nodule numbers per plant (average \pm standard deviation) were determined from at least 17 plants per strain. Results are from two independent experiments. Nodule numbers with the double-mutant strain are significantly lower than with the wild type or single mutants $(P<0.01)$. activate the calmodulin-dependent cya of Bordetella pertussis, it can be used as reporter (Sory and Cornelis 1994). The cya reporter was fused to amino acids 1 (strain BJD727), 111 (strain BJD728), and 484 (strain BJD729) of NopE1 (Fig. 2A). The reporter gene constructs were integrated into the chromosome at the original nopE1 locus by homologous recombination, which leads to the expression of the fusion proteins from the native nopEl promoter. This promoter was previously shown to be active in nodules of M. atropurpureum (Zehner et al. 2008). The activities of the cya reporter strains were measured from nodules of $M$. atropurpureum 14 days after inoculation (Fig. 2B). Nodules formed by strain BJD727 contained very low levels of cAMP, similar to wild-type infected nodules, indicating that the reporter protein resides in the bacterial cell. Significantly more reporter activities were observed in nodules formed by the strains BJD728 and BJD729 $(P<0.05)$,
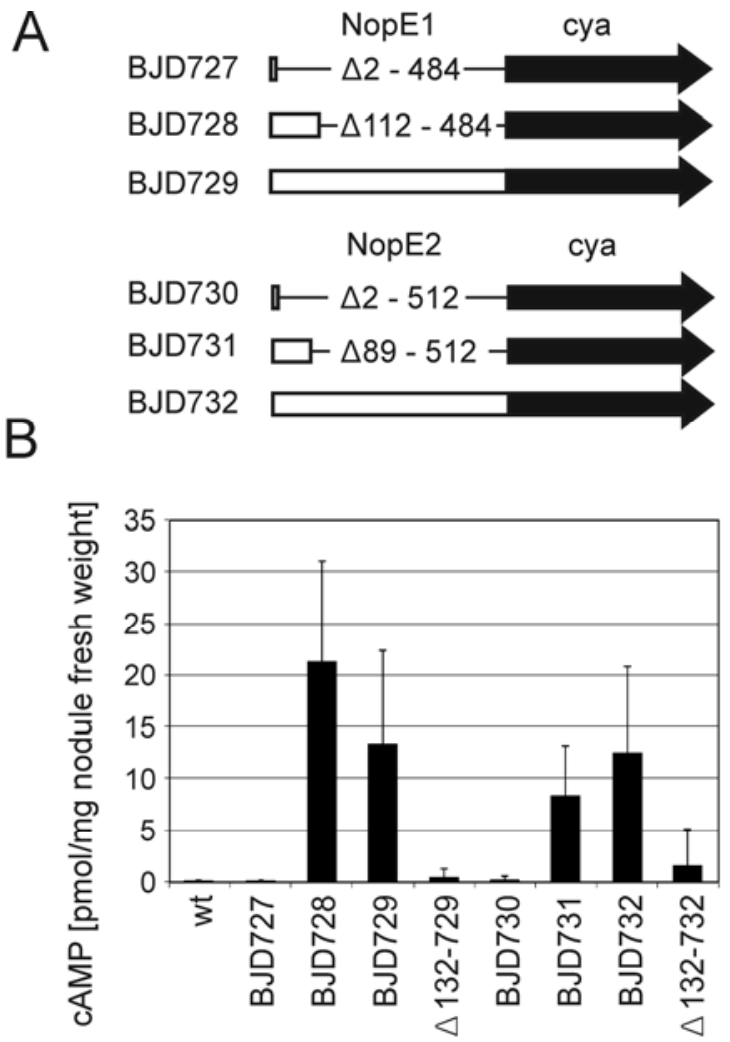

Fig. 2. cAMP levels in nodules of Macroptilium atropurpureum infected with wild type or strains encoding different NopE1- and NopE2-cya fusions. A, Schematic representation of the fusion sites. The numbers indicate the amino acid residues that are deleted within the respective fusion. B, cAMP levels measured with nodules 14 days after inoculation with the indicated strain. Values obtained for the wild type infected nodules are in the same range as reported for other legumes (Terakado et al. 1997). The experiments were performed in triplicate. $\mathrm{Wt}$ = wild type containing no cya reporter.

Table 1. Nodulation properties of Bradyrhizobium japonicum wild type and mutant derivatives on Vigna radiata cv. KPS2 ${ }^{\mathrm{a}}$

\begin{tabular}{|c|c|c|c|c|}
\hline Strain used for inoculation & Nodulated plants & Nonnodulated plants & Plants tested & Nodulation efficiency ( $\%$ ) \\
\hline Wild type & 6 & 33 & 39 & 15 \\
\hline $\mathrm{BJD} \Delta 718$ & 3 & 39 & 42 & 7 \\
\hline BJD215 & 1 & 43 & 44 & 2 \\
\hline$\Delta \mathrm{BJD} \Delta 718-\mathrm{BJD} 215$ & 32 & 5 & 37 & 86 \\
\hline BJD $\Delta 718-\Delta 644$ & 21 & 2 & 23 & 91 \\
\hline$\Delta 132$ & 22 & 1 & 23 & 96 \\
\hline BJD735 & 5 & 19 & 24 & 21 \\
\hline BJD740 & 21 & 3 & 24 & 88 \\
\hline
\end{tabular}

${ }^{a}$ Nodulation efficiency $(\%)=$ (number of nodulated plants/number of tested plants) $\times 100$. Results are from at least two independent experiments. Nodules were counted 25 days after inoculation. All observed nodules were pink and of similar size. 
suggesting that fusion proteins containing the first 111 amino acids of NopE1 or the full-length protein are translocated into the plant cell compartment. These results also indicate that the secretion signal of NopE1 locates in the N-terminal part of the protein. Similar experiments were performed with NopE2. The cya reporter was fused to amino acids 1 (strain BJD730), 88 (strain BJD731), and 512 (strain BJD732) of NopE2 and integrated at the original nopE2 locus (Fig. 2A). The reporter activity in nodules formed by strain BJD730 was significantly less $(P<0.01)$ than in nodules formed by BJD731 and BJD732 (Fig. 2B), indicating that NopE2 is translocated into the host cell compartment in the presence of an N-terminal signal that is likely to be located in the first 88 amino acids.

As control, the full-length NopE1- and NopE2-cya fusions were integrated into type III secretion mutant $\Delta 132$ (Fig. 2B, strains $\Delta 132-729$ and $\Delta 132-732)$. As expected, the cAMP values in nodules were significantly lower than for the same fusions in the wild-type background (BJD729 and BJD732; $P<$ 0.01 and 0.02 , respectively), indicating that NopE1 and NopE2 require the T3SS for transport into the host cell compartment.

\section{NopE1 is a secreted protein}

with two specific autoproteolytic cleavage sites.

Fragments of NopE1 can be found in the supernatant of $B$. japonicum cultures (Süß et al. 2006). For further biochemical characterization of the full-length protein, NopE1 was expressed in Escherichia coli as glutathione $S$-transferase (GST) fusion protein, and the GST tag was removed after purification. Because bioinformatic analysis with the SMART program (Letunic et al. 2006; Schultz et al. 1998) indicated that NopE1 contains two EF hand-like calcium-binding motifs within the DUF1521 domains (at amino acid positions 149 to 167 and 361 to 391), NopE1 was incubated with $\mathrm{Ca}^{2+}$, revealing that NopE1, which has a molecular mass of $51 \mathrm{kDa}$, is cleaved into three fragments in the presence of free $\mathrm{Ca}^{2+}$, one of about $23 \mathrm{kDa}$, and two of about $14 \mathrm{kDa}$ (Fig. 3). The cleavage can be inhibited by addition of EDTA or EGTA but not by the Complete-Mini protease inhibitor mix or the protease inhibitor 1,10-phenanthroline (data not shown).

Because the two smaller fragments are not separated well by sodium dodecyl sulfate-polyacrylamide gel electrophoresis (SDS-PAGE), the following experiments were done with the full-length GST-NopE1 fusion protein, which gave three welldistinguished fragments (Fig. 4). Internal cleavage sites were analyzed by Edman degradation of fragments $\mathrm{c}$ and $\mathrm{d}$ (Fig. 4A), which yielded the sequence PHVDA in both cases. Both sequences are located inside the conserved DUF1521 domains (Fig. 4B). The cleavage sites of NopE1 were further analyzed by site-specific mutagenesis. Eight amino acids surrounding

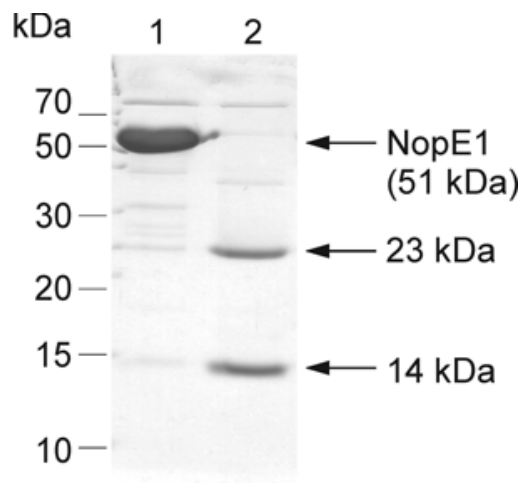

Fig. 3. Fragmentation of NopE1 in the presence of $\mathrm{Ca}^{2+}$. Purified NopE1 was incubated in $\mathrm{TKE}_{10}$ buffer (lane 1) containing $20 \mathrm{mM} \mathrm{CaCl}_{2}$ (lane 2). the C-terminal cleavage site ( $\mathrm{IKGD}_{359}$ 'PHVD) were replaced individually by alanine (Fig. 4B and C). The substitution of aspartate $\left(\mathrm{D}_{359}\right)$ or proline $\left(\mathrm{P}_{360}\right)$ prevented autoproteolysis at this position, resulting in only two fragments. The replacement of the residues $\mathrm{I}_{356}, \mathrm{~K}_{357}, \mathrm{G}_{358}, \mathrm{H}_{361}, \mathrm{~V}_{362}, \mathrm{D}_{363}$, and $\mathrm{H}_{145}$ did not inhibit fragmentation. Simultaneous exchange of residues $\mathrm{D}_{147}$ and $\mathrm{D}_{359}$ to alanine resulted in a noncleavable NopE1 derivative (Fig. 4C).

\section{Relevance of NopE1 cleavage in symbiosis.}

To test if cleavage is essential for the physiological function of NopE1, plasmids encoding the wild-type NopE1 (pBJD735) or a noncleavable NopE1 derivative (pBJD740) were integrated into the chromosome of the nopE1/nopE2 deletion mutant BJD $\Delta 718-\Delta 644$. The resulting strains were used to inoculate Vigna radiata KPS2, and nodulation efficiency was analyzed 25 days after inoculation (Table 1). Plants inoculated with strain BJD735 (complementation with wild-type nopE1) showed weak nodulation efficiency (21\%), which is similar to B. japonicum wild type (15\%). In contrast, strain BJD740 induced formation of nodules on $88 \%$ of the tested plants. A similar nodulation efficiency was observed when plants were inoculated with the nopE1/nopE2 deletion mutant (91\%). These results suggest that the noncleavable NopE1 variant is not active.

\section{A}

\section{GST-NopE1 (77.6 kDa)}

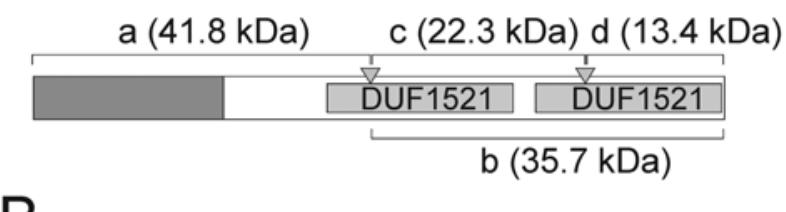

B

$$
\text { 1441 HG D PHVDA } 3561 K G D^{\nabla} P H V D A
$$

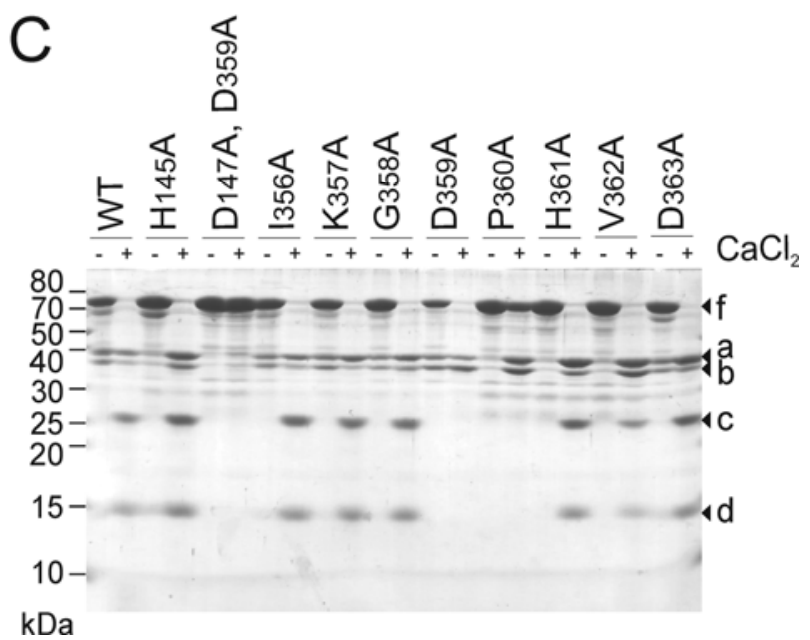

Fig. 4. Characterization of the NopE1 cleavage sites. A, Scheme of GSTNopE1 fragmentation. Sizes of fragments a-d are depicted. Filled arrowheads indicate the position of the identified cleavage sites. B, Amino acid sequence at the cleavage sites of both DUF1521 domains. Sites were determined by Edman degradation. C, Amino acid exchanges at the C-terminal cleavage site of NopE1 revealed two essential residues $\mathrm{D}_{359}$ and $\mathrm{P}_{360}$. Other amino acid substitutions did not prevent cleavage. Concurrent exchange of $\mathrm{D}_{147}$ and $\mathrm{D}_{359}$ lead to a non-cleavable variant. Full length protein GST-NopE1 is labeled with $\mathrm{f}$, released fragments are labeled with $\mathrm{a}, \mathrm{b}$, $\mathrm{c}$, and $\mathrm{d}$ as depicted in A. Fragments a and c consistently showed a slightly aberrant mobility. WT, wild-type protein. 


\section{DISCUSSION}

The presence of a functional T3SS was found to affect nodulation with soybean and $M$. atropurpureum positively (Krause et al. 2002a). Nodulation phenotype of a nopE1/nopE2 double mutant suggests that the positive effect is at least partially due to the activity of the NopE proteins. Plant assays with $V$. radiata KPS2 indicate that NopE proteins are major negative effectors for nodulation with this plant variety. In this case, they might be recognized as "pathogen-associated molecular patterns" that induce a defense reaction. That effector proteins can act positively on one host and negatively on another host has also been shown for Rhizobium sp. strain NGR234 (Kambara et al. 2009). Because single mutants in nopE1 or nopE2 displayed a phenotype similar to the wild type, NopE1 and NopE2, which are $77 \%$ identical on the amino acid level, are likely to overlap functionally.

In previous work, NopE1 and NopE2 were found solely in fragmented form in the supernatant of B. japonicum cultures, which suggests that post-secretion processing or degradation, or both, takes place (Süß et al. 2006). Interestingly, NopE1 could be isolated in full-length form from E. coli, and cleavage could be induced after purification. Because of the elaborate purification procedure and the insensitivity to protease inhibitors, it seems unlikely that cleavage is caused by a specific but unknown protease that is copurified from E. coli and also present and secreted in B. japonicum. The dependency of the cleavage on calcium ions and the prediction of calcium-binding motifs in NopE1 suggest that NopE1 has autoproteolytic activity. Moreover, complementation analysis indicates a physiological requirement for the cleavage of NopE1. Examples of type III-secreted proteins that are activated by an autoproteolytic cleavage event are HopAR1 (formerly AvrPphB) of Pseudomonas syringae pv. phaseolicola (Puri et al. 1997; Shao et al. 2002, 2003) and AvrRpt2 of Pseudomonas syringae DC3000 pv. tomato (Coaker et al. 2005, 2006; Mudgett and Staskawicz 1999). Both proteins are members of cystein protease families and involved in pathogenic interaction with host plants. In rhizobia, only NopT, which is a YopT-like protein, has been shown to exhibit some autoproteolytic activity (Dai et al. 2008; Kambara et al. 2009).

NopE1 is cleaved at two sites between aspartate and proline, which are within a conserved sequence context close to the predicted EF hand-like motifs (Fig. 5). The sequence of the cleavage sites is conserved in NopE2, suggesting an identical processing. Alanine scanning of the $\mathrm{C}$-terminal cleavage site of NopE1 showed that only the aspartate and proline next to the cleavage site are essential for cleavage. However, the sequence motif "DP" is not sufficient, as it is not cleaved at another position in NopE1.

NopE1 has no obvious similarity to known protease families and cleavage may be the result of a nonprotease reaction. Such mechanisms have been proposed for several nonhomologous proteins of different functions. A calcium-dependent "clip and link" mechanism was described for FrpC of Neisseria meningitidis (Osička et al. 2004), which is also cleaved between aspartate and proline. In this case, the processing is concerted with a linkage of the aspartate to an $\varepsilon$-amino group of lysine, resulting in an intermolecular protein cross-linking. This is in contrast to NopE1, for which higher molecular-weight fragments were never observed. YscU-like proteins, representing a conserved component of the type III and flagellar secretion apparatus were also shown to be processed by a nonprotease mechanism (Ferris et al. 2005; Wiesand et al. 2008).

Calcium is important for signal transduction in eukaryotic cells (Trewavas and Malhó 1998). Legume root hairs, for example, respond to Nod factors with calcium spiking (Ehrhardt et al. 1996; Oldroyd and Downie 2004). NopE1 might be transported as a preprotein into the plant cytosol and activated by calcium-dependent processing. In E. coli cells, NopE1 is produced as full-length protein in soluble form. This suggests that either the estimated intracellular calcium concentration of about $90 \mathrm{nM}$ (Gangola and Rosen 1987) is too low to induce cleavage or that the intracellular NopE1 does not have a conformation that is required for cleavage. In plant cells, calcium concentrations can be considerably higher and reach the micromolar range if signaling is induced by an extracellular stimulus (Ehrhardt et al. 1996; Pauly et al. 2000).

The transport of NopE1 and NopE2 into the nodule cell compartment was proven by cya reporter assay. The activity of the reporter protein is dependent on ATP and calmodulin-like proteins. Both components are present in the plant cell cytosol. Calmodulin-like proteins were also reported to be present in the symbiosome space that immediately surrounds the bacterium (Liu et al. 2006; Webb et al. 2000). There is no evidence that ATP is available in the symbiosome space. Thus, the observed increased cAMP levels with constructs in which the reporter was fused to $\mathrm{N}$-terminal peptides of the NopE proteins or the full-length proteins are most likely derived from the plant cytosol.

NopE1 and NopE2, so far known as secreted proteins of $B$. japonicum (Süß et al. 2006), were identified as positive and negative effectors in the interaction with different legumes. Using the cya reporter, the transport of effector proteins into the plant cell compartment of nodules was demonstrated for the first time. An unusual autocleavage activity of the NopE1 protein is required for effector function in the plant. Further studies are needed to identify interacting molecules within the cell.

\section{MATERIALS AND METHODS}

\section{Bacterial strains, plasmids and growth conditions.}

Strains and plasmids used in this study are listed in Supplementary Table S1. For expression of proteins, Escherichia coli cells were grown in Luria-Bertani (LB) broth at $30^{\circ} \mathrm{C}$ with appropriate antibiotic until the optical density at $600 \mathrm{~nm}$ reached 0.7 . Cells were induced by adding $200 \mu \mathrm{M}$ isopropyl$\beta$-D-thiogalactoside and were further incubated for 3 to $4 \mathrm{~h}$. $B$. japonicum was grown in peptone salts yeast extract medium (Regensburger and Hennecke 1983) for conjugation and plant assays or in arabinose-gluconate medium (Sadowsky et al. 1987) for routine growth.

\section{Generation of nopE1 and nopE2 mutants and of constructs for complementation analyses.}

For deletion of nopE1, pBJD113 was cut with BglII and $S p l I$, thereby removing the first 1,317 bp of nopE1. The protruding ends were filled in with Klenow enzyme, and a SmaI fragment containing the aadA gene of pHP45 $\Omega$ (Prentki and Krisch 1984) was inserted. The modified insert of pBJD113 was cloned into pSUPPOL2SCA (Krause et al. 2002a), generating pBJD718. The plasmid was transferred into B. japonicum by conjugation as described previously (Krause et al. 2002a). Double crossover resulted in the streptomycin-resistant mutant

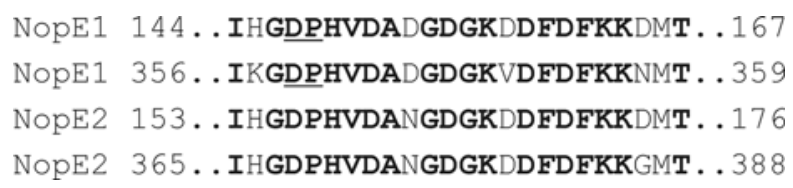

Fig. 5. Comparison of NopE1 cleavage sites with NopE2. Cleavage takes place between the conserved amino acids D and $\mathrm{P}$ (underlined). Conserved amino acids are in bold. Numbers depict amino acid positions in the proteins. 
BJD 4718 . For disruption of nopE2 (formerly blr1649), an internal 466-bp fragment was amplified by polymerase chain reaction (PCR) and was cloned into pSUPPOL2SCA (Krause et al. 2002a), resulting in plasmid pBJD215. The plasmid was transferred into $B$. japonicum by conjugation. Homologous recombination resulted in plasmid cointegration and disruption of nopE2 $2 \Delta$ (strain BJD215). The double mutant strain BJD $\Delta 718-215$ was generated by cointegration of plasmid pBJD215 in strain BJD $\Delta 718$.

For deletion of nopE2, two fragments adjacent to the nopE2 locus were amplified and cloned into pSUPPOL2SCA. A kanamycin-resistance cassette was cloned between these fragments, resulting in plasmid pBJD644. The plasmid pBJD644 was mobilized into the nopE1 deletion strain $B$. japonicum BJD $\Delta 718$ as described previously (Krause et al. 2002a). Homologous recombination resulted in strain B. japonicum BJD $\Delta 718-\Delta 644$, in which nopE1 and nopE2 are deleted.

For complementation, a 3-kb ClaI fragment of pBJD113 containing bll1804, bll1805, and nopE1 was cloned into pSUPPOL2SCA. The resulting plasmid pBJD735 was integrated into the genome of BJD $\Delta 718-\Delta 644$, thereby generating strain BJD735. Correct integration was confirmed by PCR. A FseI-NotI fragment, encoding a noncleavable NopE1 variant, was excised from the plasmid pBJD216 $6_{\mathrm{D} 147 \mathrm{~A}, \mathrm{D} 359 \mathrm{~A}}$ and was used to replace the nopE1 gene of pBJD735, resulting in plasmid pBJD740. Correct cloning was confirmed by sequencing. The plasmid was integrated into the genome of BJD $\Delta 718$ $\Delta 644$ resulting in strain BJD740.

\section{Nodulation assays.}

Seeds of soybean (Glycine max cv. Amphor) and Macroptilium atropurpureum cv. Aztec Atro were obtained from Rustica Semences (Blagnac, France) and Southedge Seeds (Mareeba, Australia), respectively. Seeds of mungbean ( $V$. radiata cv. KPS2) were a gift from N. Teaumroong (Suranaree University of Technology, Thailand). Seeds were surface-sterilized, germinated, and inoculated with B. japonicum as described previously (Krause et al. 2002a). The statistical significance of the results was calculated using analysis of variance between groups $(\alpha=0.01)$.

\section{Construction and chromosomal integration of translational nopE1- and nopE2-cya fusions.}

The cya reporter gene from pMS107 (Sory and Cornelis 1994) was amplified by PCR and was cloned into the $X b a I$ and NotI sites of the vector pSUPPOL2SCA, thereby generating plasmid pSLC5. Fragments of nopE1 and nopE2 genomic regions were amplified by PCR and were cloned into the EcoRI and $\mathrm{XbaI}$ sites of pSLC5, resulting in plasmids pBJD727, pBJD728, and pBJD729 for nopE1 fusions and pBJD730, pBJD731, and pBJD732 for nopE2 fusions. The inserts were confirmed by DNA sequencing. Recombinant plasmids were transferred into $B$. japonicum wild type and $\Delta 132$ by biparental conjugation as described previously (Krause et al. 2002a). The correct integration of the plasmids into the chromosome of B. japonicum was confirmed by PCR.

\section{Cya assays.}

To determine cAMP levels, root nodules were collected 14 days after inoculation, were frozen in liquid nitrogen, were ground to a powder, and were suspended in $10 \times$ volume of 0.1 $\mathrm{M} \mathrm{HCl}$ (per nodule weight). The suspension was centrifuged and the supernatant was used for cAMP measurement with the cyclic AMP (direct) EIA kit (Assay Designs Inc., Ann Arbor, MI, U.S.A.) according to the manufacturer's instructions. Each sample was diluted for quantification to measure cAMP concentration in the detection range of the assay.
Expression of NopE1

as glutathione $S$-transferase fusion protein.

nopE1 was amplified by PCR and was cloned into the vector pGEX-4T3 resulting in plasmid pBJD216 (gst-nopE1), which was transformed into BL21(DE3). For protein purification, cells were grown as described above, were harvested, and were washed with phosphate buffered saline. The cells were resuspended in $\mathrm{TKE}_{10}$-buffer $(100 \mathrm{mM}$ Tris-Cl, $200 \mathrm{mM} \mathrm{KCl}, 10$ mM, EDTA pH 7.5), were incubated with $1 \%$ lysozyme for 30 min on ice, and were disrupted by sonication. Cell debris was removed by centrifugation $\left(10,000 \times g, 10 \mathrm{~min}, 4^{\circ} \mathrm{C}\right)$. The cleared lysate was filtered through a $0.25-\mu \mathrm{m}$ filter and was loaded on a "GSTrap FF" affinity column (GE Healthcare, Chalfont St. Giles, U.K.). The column was washed to remove unbound protein. By adding $80 \mathrm{U}$ thrombin (GE Healthcare) to the column and with overnight incubation, NopE1 was cleaved from GST and eluted from the column. For purification of GSTNopE1 fusion protein, thrombin cleavage was omitted and elution was performed with $10 \mathrm{mM}$ reduced glutathione in $\mathrm{TKE}_{10}$ buffer. Eluates were collected and stored at $4{ }^{\circ} \mathrm{C}$ until use. Alternatively, GST-NopE1 variants were purified using Glutathione Sepharose 4 Fast Flow (GE Healthcare) slurry. The supernatant, wash buffer, and eluates were separated from the slurry by centrifugation $\left(400 \times g, 4^{\circ} \mathrm{C}\right)$.

\section{Determination of $\mathrm{N}$-terminal sequences by Edman degradation.}

Purified protein was incubated with $50 \mathrm{mM} \mathrm{CaCl}$ for 10 min at $20^{\circ} \mathrm{C}$ and was subsequently loaded on a $12 \%$ SDS polyacrylamide gel. The gel-separated bands were blotted onto a polyvinylidene diflouride membrane (Hybond P, GE Healthcare) in a semidry blotting chamber $\left(1.5 \mathrm{~mA} / \mathrm{cm}^{2}, 1 \mathrm{~h}\right)$ in a discontinuous buffer system containing Tris-CAPS (cleaved amplified polymorphic sequence) buffer $(60 \mathrm{mM}$ Tris, $40 \mathrm{mM}$ CAPS). The membrane was stained with Coomassie brilliant blue R250 and dried. The bands were cut out and analyzed by ChromaTec GmbH (Greifswald, Germany).

\section{Site-directed mutagenesis of NopE1.}

For site-directed mutagenesis, the QuikChange strategy (Stratagene, Cedar Creek, TX, U.S.A.) was used with pBJD216 as target and high-performance liquid chromatography-purified oligonucleotides containing the desired nucleotide changes (Supplementary Table S2). The modified sequence of the resulting derivatives was confirmed by sequencing.

\section{Biochemical characterization of NopE1.}

To test the effect of protease inhibitors, NopE1 was incubated $30 \mathrm{~min}$ at room temperature with $10 \mathrm{mM} \mathrm{1,10-phenanthroline}$ or Complete-Mini protease inhibitor mix (Roche, Penzberg, Germany), followed by the addition of $1 / 10$ volume of $0.25 \mathrm{M}$ $\mathrm{CaCl}_{2}$ solution. Protein fragmentation was subsequently analyzed by SDS-PAGE.

\section{ACKNOWLEDGMENTS}

We thank G. Cornelis (University of Basel, Switzerland) for providing plasmid pMS107 and N. Teaumroong (Suranaree University of Technology, Thailand) for kindly providing mungbean seeds. We are grateful to S. Okazaki (Nara Women's University, Nara, Japan) for helpful discussions. This work was supported by the Department of Biology, Dresden University of Technology.

\section{LITERATURE CITED}

Bartsev, A. V., Boukli, N. M., Deakin, W. J., Staehelin, C., and Broughton, W. J. 2003. Purification and phosphorylation of the effector protein NopL from Rhizobium sp. NGR234. FEBS (Fed. Eur. Biochem. Soc.) 
Lett. 554:271-274.

Coaker, G., Falick, A., and Staskawicz, B. 2005. Activation of a phytopathogenic bacterial effector protein by a eukaryotic cyclophilin. Science 308:548-550.

Coaker, G., Zhu, G., Ding, Z., Van Doren, S. R., and Staskawicz, B. 2006. Eukaryotic cyclophilin as a molecular switch for effector activation. Mol. Microbiol. 61:1485-1496.

Dai, W. J., Zeng, Y., Xie, Z. P., and Staehelin, C. 2008. Symbiosis-promoting and deleterious effects of NopT, a novel type 3 effector of Rhizobium sp. strain NGR234. J. Bacteriol. 190:5101-5110.

de Lyra, M. C. C. P., López-Baena, F. J., Madinabeitia, N., Vinardell, J. M., Espuny, M. R., Cubo, M. T., Belloguín, R. A., Ruiz-Sainz, J. E., and Ollero, F. J. 2006. Inactivation of the Sinorhizobium fredii HH103 rhcJ gene abolishes nodulation outer proteins (Nops) secretion and decreases the symbiotic capacity with soybean. Int. Microbiol. 9:125-133.

Deakin, W. J., Marie, C., Saad, M. M., Krishnan, H. B., and Broughton, W. J. 2005. NopA is associated with cell surface appendages produced by the type III secretion system of Rhizobium sp. strain NGR234. Mol. Plant-Microbe Interact. 18:499-507.

Ehrhardt, D. W., Wais, R., and Long, S. R. 1996. Calcium spiking in plant root hairs responding to Rhizobium nodulation signals. Cell 85:673681

Ferris, H. U., Furukawa, Y., Minamino, T., Kroetz, M. B., Kihara, M., Namba, K., and Macnab, R. M. 2005. FlhB regulates ordered export of flagellar components via autocleavage mechanism. J. Biol. Chem. 280:41236-41242.

Gangola, P., and Rosen, B. P. 1987. Maintenance of intracellular calcium in Escherichia coli. J. Biol. Chem. 262:12570-12574.

Göttfert, M., Röthlisberger, S., Kündig, C., Beck, C., Marty, R., and Hennecke, H. 2001. Potential symbiosis-specific genes uncovered by sequencing a 410-kilobase DNA region of the Bradyrhizobium japonicum chromosome. J. Bacteriol. 183:1405-1412.

Hempel, J., Zehner, S., Göttfert, M., and Patschkowski, T. 2009. Analysis of the secretome of the soybean symbiont Bradyrhizobium japonicum. J. Biotechnol. 140:51-58.

Heusipp, G., Spekker, K., Brast, S., Fälker, S., and Schmidt, M. A. 2006. YopM of Yersinia enterocolitica specifically interacts with $\alpha 1$-antitrypsin without affecting the anti-protease activity. Microbiology 152:13271335 .

Kambara, K., Ardissone, S., Kobayashi, H., Saad, M. M., Schumpp, O. Broughton, W. J., and Deakin, W. J. 2009. Rhizobia utilize pathogenlike effector proteins during symbiosis. Mol. Microbiol. 71:92-106.

Kaneko, T., Nakamura, Y., Sato, S., Asamizu, E., Kato, T., Sasamoto, S. Watanabe, A., Idesawa, K., Ishikawa, A., Kawashima, K., Kimura, T., Kishida, Y., Kiyokawa, C., Kohara, M., Matsumoto, M., Matsuno, A., Mochizuki, Y., Nakayama, S., Nakazaki, N., Shimpo, S., Sugimoto, M., Takeuchi, C., Yamada, M., and Tabata, S. 2000. Complete genome structure of the nitrogen-fixing symbiotic bacterium Mesorhizobium loti. DNA Res. 7:331-338.

Krause, A., Doerfel, A., and Göttfert, M. 2002a. Mutational and transcriptional analysis of the type III secretion system of Bradyrhizobium japonicum. Mol. Plant-Microbe Interact. 15:1228-1235.

Krause, A., Doerfel, A., Schmid, C., Hennecke, H., Krishnan, H., and Göttfert, M. 2002b. The type III secretion system of Bradyrhizobium japonicum 110spc4. Pages 288-292 in: Nitrogen Fixation: Global Perspectives. T. M. Finan, M. R. O’Brian, D. B. Layzell, J. K. Vessey, and W. Newton, eds. CABI Publishing, CAB International, Wallingford, U.K.

Krishnan, H. B., Lorio, J., Kim, W. S., Jiang, G., Kim, K. Y., DeBoer, M., and Pueppke S. G. 2003. Extracellular proteins involved in soybean cultivar-specific nodulation are associated with pilus-like surface appendages and exported by a type III protein secretion system in Sinorhizobium fredii USDA257. Mol. Plant-Microbe Interact. 16:617-625.

Letunic, I., Copley, R. R., Pils, B., Pinkert, S., Schultz, J., and Bork, P. 2006. SMART 5: Domains in the context of genomes and networks. Nucleic Acids Res. 34:D257-D260.

Liu, J., Miller, S. S., Graham, M., Bucciarelli, B., Catalano, C. M., Sherrier, D. J., Samac, D. A., Ivashuta, S., Fedorova, M., Matsumoto, P., Gantt, J. S., and Vance, C. P. 2006. Recruitment of novel calcium-binding proteins for root nodule symbiosis in Medicago truncatula. Plant Physiol. 141:167-177.

Lorio, J. C., Kim, W. S., and Krishnan, H. B. 2004. NopB, a soybean cultivar-specificity protein from Sinorhizobium fredii USDA257, is a type III secreted protein. Mol. Plant-Microbe Interact. 17:1259-1268.

Marie, C., Deakin, W. J., Viprey, V., Kopcinska, J., Golinowski, W., Krishnan, H. B., Perret, X., and Broughton, W. J. 2003. Characterization of Nops, nodulation outer proteins, secreted via the type III secretion system of NGR234. Mol. Plant-Microbe Interact. 16:743-751.

Meinhardt, L. W., Krishnan, H. B., Balatti, P. A., and Pueppke, S. G. 1993. Molecular cloning and characterization of a sym plasmid locus that regulates cultivar-specific nodulation of soybean by Rhizobium fredii USDA257. Mol. Microbiol. 9:17-29.

Mudgett, M. B., and Staskawicz, B. J. 1999. Characterization of the Pseudomonas syringae pv. tomato AvrRpt 2 protein: Demonstration of secretion and processing during bacterial pathogenesis. Mol. Microbiol. 32:927-941.

Oldroyd, G. E. D., and Downie, J. A. 2004. Calcium, kinases and nodulation signalling in legumes. Nat. Rev. Mol. Cell Biol. 5:566-576.

Osička, R., Procházková, K., Sulc, M., Linhartová, I., Havlícek, V., and Sebo, P. 2004. A novel "clip-and-link" activity of repeat in toxin (RTX) proteins from gram-negative pathogens. Covalent protein cross-linking by an Asp-Lys isopeptide bond upon calcium-dependent processing at an Asp-Pro bond. J. Biol. Chem. 279:24944-24956.

Pauly, N., Knight, M. R., Thuleau, P., van der Luit, A. H., Moreau, M., Trewavas, A. J., Ranjeva, R., and Mazars, C. 2000. Control of free calcium in plant cell nuclei. Nature 405:754-755.

Prentki, P., and Krisch, H. M. 1984. In vitro insertional mutagenesis with a selectable DNA fragment. Gene 29:303-313.

Puri, N., Jenner, C., Bennett, M., Stewart, R., Mansfield, J., Lyons, N., and Taylor, J. 1997. Expression of avrPphB, an avirulence gene from Pseudomonas syringae pv. phaseolicola, and the delivery of signals causing the hypersensitive reaction in bean. Mol. Plant-Microbe Interact. 10:247-256.

Regensburger, B., and Hennecke, H. 1983. RNA polymerase from Rhizobium japonicum. Arch. Microbiol. 135:103-109.

Rodrigues, J. A., López-Baena, F. J., Ollero, F. J., Vinardell, J. M., Espuny, M. R., Bellogin, R. A., Ruiz-Sainz, J. E., Thomas, J. R., Sumpton, D., Ault, J., and Thomas-Oates, J. 2007. NopM and NopD are rhizobial nodulation outer proteins: Identification using LC-MALDI and LC-ESI with a monolithic capillary column. J. Proteome Res. 6:1029-1037.

Saad, M. M., Kobayashi, H., Marie, C., Brown, I. R., Mansfield, J. W., Broughton, W. J., and Deakin, W. J. 2005. NopB, a type III secreted protein of Rhizobium sp. strain NGR234, is associated with pilus-like surface appendages. J. Bacteriol. 187:1173-1181.

Sadowsky, M. J., Tully, R. E., Cregan, P. B., and Keyser, H. H. 1987. Genetic diversity in Bradyrhizobium japonicum serogroup 123 and its relation to genotype-specific nodulation of soybean. Appl. Environ. Microbiol. 53:2624-2630.

Schultz, J., Milpetz, F., Bork, P., and Ponting, C. P. 1998. SMART, a simple modular architecture research tool: Identification of signaling domains. Proc. Natl. Acad. Sci. U.S.A. 95:5857-5864.

Shao, F., Merritt, P. M., Bao, Z., Innes, R. W., and Dixon, J. E. 2002. A Yersinia effector and a Pseudomonas avirulence protein define a family of cysteine proteases functioning in bacterial pathogenesis. Cell 109:575-588

Shao, F., Vacratsis, P. O., Bao, Z., Bowers, K. E., Fierke, C. A., and Dixon, J. E. 2003. Biochemical characterization of the Yersinia YopT protease: Cleavage site and recognition elements in Rho GTPases. Proc. Natl. Acad. Sci. U.S.A. 100:904-909.

Sory, M. P., and Cornelis, G. R. 1994. Translocation of a hybrid YopEadenylate cyclase from Yersinia enterocolitica into HeLa cells. Mol. Microbiol. 14:583-594

Skorpil, P., Saad, M. M., Boukli, N. M., Kobayashi, H., Ares-Orpel, F., Broughton, W. J., and Deakin, W. J. 2005. NopP, a phosphorylated effector of Rhizobium sp. strain NGR234, is a major determinant of nodulation of the tropical legumes Flemingia congesta and Tephrosia vogelii. Mol. Microbiol. 57:1304-1317.

Süß, C., Hempel, J., Zehner, S., Krause, A., Patschkowski, T., and Göttfert, M. 2006. Identification of genistein-inducible and type III-secreted proteins of Bradyrhizobium japonicum. J. Biotechnol. 126:69-77.

Terakado, J., Okamura, M., Fujihara, S., Ohmori, M., and Yoneyama, T. 1997. Cyclic AMP in rhizobia and symbiotic nodules. Ann. Bot. 80:499-503.

Trewavas, A. J., and Malhó, R. 1998. $\mathrm{Ca}^{2+}$ signalling in plant cells: The big network! Curr. Opin. Plant Biol. 1:428-433.

Viprey, V., Del Greco, A., Golinowski, W., Broughton, W. J., and Perret, X. 1998. Symbiotic implications of type III protein secretion machinery in Rhizobium. Mol. Microbiol. 28:1381-1389.

Webb, K. J., Skøt, L., Nicholson, M. N., Jørgensen, B., and Mizen, S. 2000. Mesorhizobium loti increases root-specific expression of a calcium-binding protein homologue identified by promoter tagging in $\mathrm{Lo}$ tus japonicus. Mol. Plant-Microbe Interact. 13:606-616.

Wiesand, U., Sorg, I., Amstutz, M., Wagner, S., van den Heuvel, J., Lührs, T., and Cornelis, G. R. 2008. Structure of the type III secretion recognition protein YscU from Yersinia enterocolitica. J. Mol. Biol. 385:854-866.

Zehner, S., Schober, G., Wenzel, M., Lang, K., and Göttfert, M. 2008. Expression of the Bradyrhizobium japonicum type III secretion system in legume nodules and analysis of the associated $t$ ts box promoter. Mol. Plant-Microbe Interact. 21:1087-1093. 